\title{
Do Financial Incentives Aimed at Decreasing Interhousehold Inequality Increase Intrahousehold Inequality?
}

\author{
Amanda Chuan, John List, and Anya Samek ${ }^{*}$
}

January 19, 2021

\begin{abstract}
Research has shown that giving disadvantaged families financial incentives to invest in their children could decrease socioeconomic inequality by enhancing human capital formation. Yet, within the household how are such gains achieved? We use a field experiment to investigate how parents allocate time when they receive financial incentives. We find that incentives increase investment in the target child. But, parents achieve these gains by substituting away from time spent with the child's sibling(s). An unintended consequence is that intrahousehold inequality increases and aggregate gains from the program are overstated when focusing only on target children.
\end{abstract}

Keywords: family economics, intrahousehold allocation, early childhood education JEL Classifications: D13, I21, I24, I26, J13, J24

\footnotetext{
* Chuan: Michigan State University School of Human Resources \& Labor Relations, 368 Farm Lane, East Lansing, MI 48842 (email: achuan@msu.edu); List: The Kenneth C. Griffin Department of Economics, University of Chicago, 1126 E. $59^{\text {th }}$ Street, Chicago, IL 60637 and NBER (email: jlist@ uchicago.edu); Samek: Rady School of Management at University of California San Diego, 9500 Gilman Drive, La Jolla, CA 92093 and NBER (email: asamek @ ucsd.edu). Support for this research was provided by the Kenneth and Anne Griffin Foundation and NIH grant 1R01DK114238. Helpful comments were provided by Clayton Featherstone, Judd Kessler, Katherine Milkman, Alex Rees-Jones, and student workshop participants at the Wharton School at the University of Pennsylvania. Outstanding assistance with the data were provided by Rene Crespin, Andre Gray, Tristin Ganter, Justin Holz, Jennie Huang, Tina Huang, Charis Li, Reuben Lobel, Phuong Ta, Mattie Toma, Karen Ye, and many others. Any errors and all opinions are our own. The research was conducted with approval from the University of Chicago Social and Behavioral Sciences Institutional Review Board, protocol H10083. The study is registered in the AEA RCT Registry, AEARCTR-0005638. Declarations of interest: none.
} 


\section{Introduction}

In the United States today, 23.5 million children are born into impoverished families (Fontenot et al., 2018). Most of these children will remain in poverty as adults, partly due to persistent skill gaps between the rich and the poor that open at early ages. One explanation behind these skill gaps is that resource-constrained parents tend to invest less in the human capital of their children (Heckman, 2006). Evidence suggests that early childhood intervention programs are society's best hope of breaking this cycle and mitigating the intergenerational transmission of poverty, since cognitive and non-cognitive skills are most sensitive to parental and environmental inputs when children are between the ages of 3 to 5 (Heckman, 2006, 2008; Del Boca et al., 2014; Heckman and Karakapula, 2019).

Mounting evidence has caused researchers to advocate for the use of financial incentives (i.e., conditional cash transfers) in policies aimed at addressing socioeconomic inequality in developed and developing countries (see J-PAL, 2013; Del Boca et al., 2016). Financial incentives have been shown to improve school attendance, school progression, test scores, physical health, teacher effort, and cognitive development (see J-PAL, 2013; Millan et al. 2019 for a review). One key limitation of financial incentives is that many of these interventions target a subset of children in the family, meaning that many families will have both targeted children and non-targeted children. How such interventions impact non-targeted children is unclear. Prior studies conducted in developing countries report mixed results, with some studies finding declines in the educational attainment of non-targeted siblings (Barrera-Osorio et al., 2011; Shrestha and Palaniswamy, 2017), one finding no effect (Ferreira et al., 2009) and some finding a positive effect on siblings' school attendance (Takamatsu, 2011; Bustelo, 2011). In all of these prior papers, a key consideration for 
the parental investment decision is the tradeoff between sending their young children to school or to work, whereas in the developed country context parents do not experience this stark tradeoff.

The type of tradeoff that parents in developed countries may experience concerns how much time to invest in teaching to each of their children. In such a setting, the open question arises about what mechanisms explain the effects of incentives on investment in target and non-target children. Financial incentives provide both a stimulus to substitute investments across children and a wealth effect (Baird et al., 2011). The substitution effect dictates that the prospect of earning money should motivate parents to invest more time in the target child's education, diverting parental inputs from other children in the family. The wealth effect dictates that when parents receive payments, the resources available to all children in the family expand. Parents could spend the money from the intervention on their children, or could cut back on work hours given the additional income, freeing up time to spend with all children. Determining the mechanisms behind the success of incentives is important for predicting the total effects of programs. Delving into these mechanisms has been difficult due to limited data on families - currently, the parental investment decision is a black box. ${ }^{1}$

In this paper, we take advantage of the Chicago Heights Early Childhood Center (CHECC), a field experiment in a disadvantaged area in the United States that provided parenting classes and offered financial incentives to spend time with one target child (Fryer et al., 2015). Since CHECC aims to study how to improve human capital among preschool-aged children, children between the ages of 3 to 5 were targeted. We compare the investment of parents randomized to two conditions. In the "immediate" condition, parents received financial rewards of up to $\$ 6,900$ in cash for investing in the target child. In the "delayed" condition, parents could receive up to the equivalent

\footnotetext{
${ }^{1}$ Indeed, Barrera-Osorio et al. (2011) point out that their results for non-targeted siblings are limited precisely due to a lack of data at the household level.
} 
amount deposited into a savings account, which they can only access if and when their target child enrolled in post-secondary education years later (usually at age 17-18). We address the knowledge gaps about the mechanisms through which incentives affect parents by honing in on a key input to the human capital production function: parental time.

We find that parents divert time away from siblings and towards target children when the financial incentive is paid out immediately, as opposed to with a delay. The intervention thus induces parents to shift resources unequally among their children. Our results indicate that by changing parents' behavior, high-powered financial incentive programs intended to mitigate interhousehold inequality may in fact exacerbate intrahousehold inequality. Additionally, we show that the reallocation of parental time is a key mechanism underlying the success of financial incentive interventions. These findings indicate that potential long-term human capital loss to nontargeted children could be especially dire, since parental time is critical for the development of cognitive and socioemotional skills among children over the lifecycle (Hill and Stafford, 1974; Leibowitz, 1974, 1977; Del Boca et al., 2014; Juhn et al., 2015).

\section{Experimental Design}

We collect data come from a large field experiment called the Chicago Heights Early Childhood Center (CHECC). CHECC operated in Chicago Heights, IL in 2010-2014 (Fryer et al., 2015). The intervention focused on low-income households with children, the majority of whom were black and Hispanic. In 2010-2012, households who registered for CHECC were randomly chosen to participate in a program called Parent Academy which provided financial incentives and workshops that encouraged parents to teach to their preschool-aged target child. In each school year, there were 18 Parent Academy workshops, 17 homework assignments, three evaluations 
conducted with the parent and the target child, and three assessments conducted with only the target child. Parents could earn up to $\$ 6,900$ per year for attending workshops, their performance with their target child on homework, their performance with their target child on evaluations, and their target child's performance on assessments. The maximum earnings amounted to over a quarter $(27.6 \%)$ of median household income for the analysis sample. Households could participate in the program for up to two years, depending on the age of the child when he or she was randomized into treatment.

We compare between the immediate and delayed financial incentive treatment arms of Parent Academy. Half of families assigned to Parent Academy were offered an immediate financial incentive, in which all rewards were paid out in cash. The other half of families received a delayed financial incentive, in which almost all earnings were deposited into a savings account that was only accessible if and when the target child enrolled in post-secondary education years later. Importantly, both the immediate and the delayed incentive groups paid parents for attending Parent Academy workshops in cash, so there is no differential attrition from the program between the two conditions (see Table 2 panel A). For performance on homework, evaluations, and assessments, the delayed financial incentive generated a much smaller reward in present discounted value than the immediate financial incentive. For example, if parents discounted future earnings at an annual rate of 5\%, each dollar received by the time their target child turned 18 would be subjectively equivalent to only 48 cents received when their target child was 3 years old. ${ }^{2}$ The Appendix elaborates on the details of the intervention, including the financial incentives for attendance, homework, evaluations, and assessments.

\footnotetext{
${ }^{2}$ For simplicity, this back of the envelope calculation assumes that parents know with certainty that their target child will enroll in postsecondary education. The earnings in the delayed condition are lower if we assume the child may not enroll in postsecondary education.
} 
We use administrative and survey data to examine parental investment across children in the family. Administrative data measure parental investment in the targeted child, while survey data measure parental investment in both the targeted child and the non-targeted siblings. The administrative data include information on Parent Academy workshop attendance, homework grades, earnings from evaluations, and earnings from assessments, which we all take as measures of parental investment in the targeted child. We also administered parent investment surveys in the middle of each school year which asked parents about the number of hours spent teaching to each child in their household on a typical weekday. ${ }^{3}$ The amount of time parents spent teaching to each child is the primary measure for parental investment in non-targeted siblings. Prior to randomization to a CHECC program, we also administered a demographic survey, which we use to control for potential confounding effects that were not addressed by the randomization.

Our analysis sample consists of 282 families with one target child in Parent Academy (89 in only the 2010-2011 school, year, 148 in only the 2011-2012 school year, and 45 in both school years). Out of this sample, 124 families have one CHECC child and at least one sibling (24 in only the 2010-2011 school year, 68 in only the 2011-2012 school year, and 32 in both school years). Table 1 describes the demographic characteristics of the full sample (panel A) and the sample with at least one non-targeted sibling (panel B). ${ }^{4}$ Columns (1) and (2) describe the mean and standard error for each variable in the delayed and immediate conditions, respectively. Column (3) lists the difference in means and associated standard error between the two conditions. Column (4) lists the t-statistic of a two-sample t-test, while column (5) presents the associated p-value. Across all

\footnotetext{
${ }^{3}$ Additional questions include whether older siblings taught younger siblings in the household, and whether parents taught multiple children at the same time.

${ }^{4}$ For the 45 families that participated in the program for two years, only the first year is used to calculate summary statistics. All characteristics were measured prior to the start of the intervention with the exception of sibling age, which was collected in the middle of the school year.
} 
measures, there appear to be no significant differences in family characteristics, suggesting that families in the immediate and delayed conditions are similar across observable characteristics. The online Appendix elaborates on the data and experimental details.

\section{Results}

In this section, we report the main effects of parental investment on target children and non-targeted siblings. We estimate the effects of the immediate incentive compared to the delayed incentive using the following OLS equation:

$$
\begin{gathered}
y_{\mathrm{i}}=\beta_{0}+\beta_{1} \mathbf{1}(\text { immediate })+\beta_{2} \mathrm{X}_{\mathrm{i}}+\beta_{3} \mathbf{1}(\text { year }=2011)+\beta_{4}(\text { years in CHECC }) \\
+\epsilon_{\mathrm{i}}
\end{gathered}
$$

where " $\mathbf{1}$ (immediate)" is a variable that equals 1 if the family is in the immediate condition and 0 if the family is in the delayed condition. The variable " $\mathbf{1}$ (year $=2011$ )" equals 1 if the year is 2011 and 0 if the year is 2010. The variable "years in CHECC" equal 1 if the family is in their first year of participation at CHECC and 2 if the family is in their second year of participating in CHECC. The vector of controls $X_{i}$ is divided into "demographic" and "additional" controls. Demographic controls consist of the gender of the target child, the age of the target child, race, and the hours the parents spend teaching to the child per weekday prior to program participation. In alternate specifications, we use additional controls which consist of average age of siblings in the family, mother's age, target child's baseline cognitive score, and target child's baseline noncognitive score. In all regressions, we include dummies for missing variables. ${ }^{5}$ For families that

\footnotetext{
${ }^{5}$ Our control variables were obtained from survey data, which changed from year to year. For example, no baseline investment measures were collected in the 2010-2011 school year. Many participants did not respond to all questions in our surveys, so only a subset of our sample have data on child mother's age and baseline scores. Less than half of our analysis sample in Table 2 have at least one sibling. These data limitations make it necessary to use dummies for missing values and to assign missing values 0 following Cohen and Cohen (1975) if we are to control for certain co-
} 
have been in CHECC for two years, we only use the demographic information collected in year 1 prior to their randomization by the CHECC lottery. Analyses were conducted at the family level. Standard errors are clustered at the family level, which is the level of randomization.

When examining investment in non-targeted siblings, we modify the regression equation above into an ordered probit regression since the outcome measures are categorical. When comparing investment in the target child and in non-targeted siblings within households, we modify the regression equation into probit regressions since the outcome measures equal 0 or 1 for whether parents invest more, less, or equal amounts in the target child relative to her siblings.

It is possible that randomization to the immediate condition may make parents multi-task in order to more efficiently invest in their children, such as teaching to both target children and non-targeted siblings simultaneously. Similarly, the immediate condition may increase the likelihood that older children or other family members to teach to the younger (targeted) children. Our investment survey, which only asks about the number of hours the parent spends actively teaching each child on a typical weekday, would then misestimate the true amount of human capital investment received by children. In follow-up surveys, we ask parents whether they teach to multiple children at the same time and whether other family members, including older siblings, teach to their young children. In robustness tests, we use these measures as additional controls in our probit and ordered probit regressions. The coefficient plots, reported in the Appendix, show no appreciable change in our estimated coefficients.

Finally, there might be concerns regarding misreporting since we use survey data to collect our measurement of time allocation. One advantage of comparing between the immediate and delayed payment conditions, rather than against a control group, is that one would not anticipate

variates. An alternative approach is to drop observations with missing data and exclude covariates with substantial missing values. Appendix Table A4 shows that our results still hold with this approach. 
the degree of misreporting to differ significantly across the two conditions, especially if misreporting is cheap talk and families correctly believe that we cannot monitor their time allocation. Furthermore, if the experimental conditions exerted differential pressure on families to conform to experimenter demand effects or social desirability bias, one would not expect those in the immediate payment condition to report lower investment in non-targeted siblings. If anything, it is more likely that pressure to conform to social desirability or experimenter demand effects would make families in the immediate payment condition report greater time spent with both target children and non-targeted siblings. In this case, our results would form lower bounds on the true differences in parental time allocation across conditions.

\section{Result 1: Investment in target children rises when payment is immediate.}

First, we find that the program has the anticipated incentive result: investment in target children is significantly higher when the financial incentives are immediate, leading to higher academic performance. Table 2 summarizes the effect of the two conditions on attendance and performance at Parent Academy, which we take to be indirect measures of investment in target children. ${ }^{6}$ Panels A-D report on the number of classes parents attended, the GPA from homework assignments, parents' earnings for their target child's performance at Parent Academy evaluations, and parents' earnings for their target child's performance at CHECC assessments. Each panel reports the coefficient and standard errors on the dummy for being randomized into the immediate instead of the delayed condition. Each panel also reports the mean and standard error of the outcome variable.

\footnotetext{
${ }^{6}$ The total number of observations in Table 2 is 326. Of the 282 families in our analysis sample, one did not attend any Parent Academy classes. For the remaining 281 families, 236 participated in CHECC for one year and are counted once, while the 45 families that participated for both years are counted twice.
} 
Column (1) controls for the school year and the total number of years the family has participated in CHECC. Column (2) adds demographic controls, and column (3) adds demographic and additional controls. All regressions are performed at the family-year level, and standard errors are clustered at the family level.

Panel A reports the results of a negative binomial regression of the number of classes attended on experiment condition. ${ }^{7}$ On average, parents attend about 13 out of 18 classes across both experimental conditions. We predict that since parents in both conditions receive earnings for attendance immediately in cash, they should attend parenting workshop classes at roughly the same rate. Indeed, our results show that randomized assignment to the immediate or delayed condition does not significantly influence the number of classes parents attend ( $p>0.10$ in all specifications), indicating that differential attrition is not a large concern with our analysis.

For all other features of Parent Academy, parents in the immediate financial incentive condition receive earnings in cash while parents in the delayed financial incentive condition can observe their earnings deposited in a savings account that is only accessible when their target child turns 18. The ordinary least squares (OLS) regressions reported in panels B-D of Table 2 show that, despite similar class attendance rates across the two conditions, immediate financial incentives lead parents to invest more in target children. Panel B reports that homework GPA tends to be about 0.3-0.4 points higher when parents are given immediate rather than delayed incentives ( $\mathrm{p}<0.05)$. Panels $\mathrm{C}$ and D examine performance on CHECC evaluations and assessments, where performance is standardized to the dollar amount of earnings received by parents in order to facilitate comparison across the child-parent evaluations and the child-only assessments. Both

\footnotetext{
${ }^{7}$ We prefer a negative binomial regression over an ordinary least squares regression when examining the count data of classes attended. First, there is high dispersion in the number of classes attended: the average is 12.83 while the variance is 47.02. Much of the mass is centered at the right tail of the distribution: over 52\% of the sample attended 17-18 classes. The OLS results are similar to the negative binomial regression results and are available upon request.
} 
panels show that target children perform better when their parents are given immediate, rather than delayed, financial incentives $(\mathrm{p}<0.05$ in panel $\mathrm{C}, \mathrm{p}<0.10$ in panel $\mathrm{D}){ }^{8}$

\section{Result 2: Investment in non-targeted siblings falls when payment is immediate.}

To achieve the gains reported in result 1, parents diverted time away from siblings and towards target children. While result 1 suggests that the program achieves its intended effect of decreasing interhousehold inequality across low and high SES groups, this second result calls this insight into question and further suggests that the program increases intrahousehold inequality. Of the 282 families, 124 families had multiple children in the household. We surveyed these parents on how much time they spent teaching to each child in their family on a typical weekday, from "none", "0-1 hour", "1-2 hours", "2-3 hours", "3-5 hours", to "5 or more hours".

Figure 1 reports the predicted probabilities estimated from an ordered probit regression of the experimental condition on these responses. Target child investments are in blue and nontargeted sibling investments are in red. Compared to the delayed condition, parents in the immediate condition are 4.6 percentage points more likely to spend no time teaching siblings on a $(\mathrm{p}<0.05)$ and 13.2 percentage points more likely to spend $0-1$ hours teaching siblings $(\mathrm{p}<0.05)$. They are 7.6 percentage points less likely to spend 2-3 hours teaching siblings $(\mathrm{p}<0.05)$, and 3.4 percentage points less likely to spend 3-5 hours teaching siblings $(\mathrm{p}<0.05)$. Predicted probabilities are derived from a regression that controls for school year, total years in CHECC, and demographic

\footnotetext{
${ }^{8}$ Across all outcomes, coefficient estimates decrease with the inclusion of additional controls, suggesting that the sample may be imbalanced. Imbalance is a common and unavoidable problem with small samples such as ours. Table 1 shows there are no significant differences in observables, but we cannot rule out that differences in unobservables could affect our estimates. We present our estimates using different sets of controls to show that our results hold under multiple specifications.
} 
characteristics. Appendix Figure A1 reports similar estimates when we add further controls for mother's age, siblings' average age, baseline assessment scores, whether the parents teach to multiple children at the same time, and whether other family members (including older siblings) teach to children. Finally, Appendix Tables A2-A3 report results using different sets of baseline controls, showing that our coefficient estimates are robust to alternative specifications.

Overall, Figure 1 demonstrates that parents' time spent teaching to siblings declined but their time spent teaching to target children did not significantly change. These results can be reconciled by the fact that Parent Academy classes are held for one hour every two weeks, requiring an average commitment of half an hour each week. Parents do not report their class attendance as time spent teaching to target children, although it is indirect time investment in target children's human capital. Therefore, time spent teaching to target children may not explicitly change in our survey data, even though homework grades and test performance in our administrative records indicate that total parental investment in target children rose. Together, Table 2 shows that parents in the immediate condition invested more in their target children, while Figure 1 shows that this change came at the expense of non-targeted siblings.

\section{Result 3: Inequality in parental investment across children within the family rises when payment is immediate.}

Our findings indicate that high-powered financial incentive programs intended to decrease interhousehold inequality might actually have an unintended effect of increasing intrahousehold inequality, acting to reverse some of the gains measured in the primary treatment. This is depicted in Figure 2, which plots predicted probabilities of probit regressions for whether parental investment in target children is greater than, equal to, or less than investment in siblings. The 
immediate condition makes parents 15.8 percentage points more likely to report investing more in target children than siblings $(\mathrm{p}<0.10)$, demonstrating the rise in intrahousehold inequality. The coefficients are estimated from regressions controlling for school year, total years in CHECC, and demographic characteristics. In alternate specifications, we also control for mother's age, siblings' age, baseline assessment scores, whether the parents teach to multiple children at the same time, and whether other family members (including older siblings) teach to children. The coefficient estimates, reported in Appendix Figure A2, are similar to those in Figure 2.

Our results suggest that the substitution effect exceeded any wealth effects, since the growth in target child investment coincided with a decline in the time parents would have spent investing in non-targeted siblings. We find little evidence of a wealth effect: parents in the immediate condition spent less time with non-targeted siblings than parents in the delayed condition, indicating that parents did not respond to the income gain by working less and spending more time with children overall. However, one important caveat is that our data are limited in describing how families used their earnings. It is possible that parents could have used their earnings to pay for tutors or afterschool classes, but we find this unlikely since there are few such services in impoverished areas like Chicago Heights, IL. Parents might also spend their earnings on household purchases that benefit the entire family, including non-targeted siblings (e.g., more nutritious meals, better health care, technological inputs that improve learning). However, prior research demonstrates that few inputs to the human capital production function are as important as parental time (see Del Boca et al., 2014; Juhn et al., 2015; Heckman, 2008). As we mention in the discussion, further work assessing the long-term human capital effects of parental time compared to other household inputs in this context would help inform whether this intrahousehold inequality in parental time widens future intrahousehold gaps in child achievement. 


\section{Result 4: Treatment effects are larger when the age difference between the target child and} siblings is large.

Does the age difference between the target child and non-targeted siblings influence investment? If siblings are close in age to the target child, parents may be more motivated to invest regardless of the financial incentive, since what they learn from Parent Academy would benefit non-targeted siblings as well. On the other hand, if there were only siblings that were far from the target child in age, the financial incentive should play a larger role in parental investment behaviors since parents would not receive the non-pecuniary benefit of applying what they learn from Parent Academy to non-targeted siblings.

To test for differences in treatment effects, we modify equation (1) above by using a dummy that equals 1 if the family has no siblings close to the target child's age. The difference in treatment effects would then be reflected in the interaction between receiving the immediate payment and having no siblings close to the target child's age. ${ }^{9}$

$$
\begin{aligned}
\mathrm{y}_{\mathrm{i}}=\beta_{0}+\beta_{1} \mathbf{1}(\text { immediate })+\beta_{2} \mathbf{1}(\text { no siblings close to target child age }) \\
+\beta_{3} \mathbf{1}(\text { immediate }) * \mathbf{1}(\text { no siblings close to target child age }) \\
+\beta_{4} \mathbf{1}(\text { year }=2011)+\beta_{5}(\text { years in CHECC })+\epsilon_{\mathrm{i}}
\end{aligned}
$$

We plot our estimates of $\beta_{3}$ in Figure 3. We vary our definition of "close to target child age" by creating separate dummies for whether there are no siblings within 2 to 6 years of the target child's age. We can therefore trace out an age gradient over which differential treatment effects might arise. We find that compared to the rest of the sample, families with no siblings within 4 and 6 years of the target child's age exhibit a significantly larger treatment

\footnotetext{
${ }^{9}$ Our sample size is already quite small, limiting our ability to detect significant interactions. To avoid decreasing the degrees of freedom even further, we only control for school year and total years in CHECC.
} 
effect on target child investment. That is, the interaction coefficient is negative for the likelihood of reporting less than one hour spent teaching the target child $(\mathrm{p}<0.10)$ and positive for reporting 2-3 hours spent teaching the target child $(\mathrm{p}<0.10)$. While our small sample size makes it difficult to estimate precise standard errors, the effects are quite consistent across specifications. Parents with no siblings close to the target child's age report directionally lower likelihoods of spending 0 hours, $<1$ hours, and 1-2 hours teaching to the target child. They report directionally higher likelihoods of spending 2-3 hours, 3-5 hours, and over 5 hours teaching to the target child.

These results show that the treatment effect for target child investment tends to be stronger among families where there are no siblings close to the target child's age. Our results indicate that families with at least one sibling close to the target child's age are less responsive to the financial incentive, potentially due to complementarities in investment across children of similar ages. An additional explanation is that since our target children are 3-5 years old, siblings that are far from the target child in age tend to be older and require less care, potentially giving parents more time to invest in target children in response to the financial incentive. ${ }^{10}$ Overall, the evidence suggests that when there are multiple children in the household, the effect of the financial incentives on target child investment are weaker when children are close together in age.

\section{Discussion and Conclusion}

We use a field experiment to examine how financial incentives influence the allocation of parental time across multiple children in the household in a developed country. Our findings are stark. The

\footnotetext{
${ }^{10}$ Since only 34 families (12\%) have non-targeted siblings that are younger than 3 years old, we lack the power to explore differential effects based on whether the non-targeted sibling is younger or older than the target child. We therefore must remain agnostic as to whether our result is driven by the age distance between siblings, whether the siblings are younger or older than the target child, or both.
} 
immediate payment significantly increases parental investment in target children, as measured by academic performance at Parent Academy. However, to achieve these gains, parents divert time away from non-targeted siblings. Our results favor a substitution story, whereby financial incentives lead parents to reallocate their time toward the child targeted by the program and away from other children in the family. We do not find evidence of a wealth effect, in which additional earnings from the program enabled parents to shift time from working to investing more in all their children.

Our study focuses on parental time, a critical input to the human capital production function (Hill and Stafford, 1974; Leibowitz, 1974, 1977; Del Boca et al., 2014; Juhn et al., 2015). Our results suggest that this shift in parental time is one key mechanism underlying the success of financial incentive interventions. We posit that the lack of consensus in prior studies may arise from their inability to separate parental time from other household resources, such as child labor hours and the time of siblings (Ferreira et al., 2009; Barrera-Osorio et al., 2011; Shrestha and Palaniswamy, 2017; Bustelo, 2011; Takamatsu, 2011). For example, in prior studies, earning financial incentives could mean siblings did not have to work outside the home as much, causing them to increase school attendance rates even as they experience less direct parental time investment.

Our results serve to warn that narrowly defined outcome metrics might send erroneous signals of program efficacy. In our case, this has direct implications for policy since parental time is among the most important assets in the human capital production of children (Hill and Stafford, 1974; Leibowitz, 1974, 1977; Juhn et al., 2015), and siblings who suffer a loss in parental time may face disadvantages in their human capital formation. Low-income parents, who are already heavily resource-constrained in terms of both time and money, may respond to conditional cash 
transfers by making difficult and irreversible decisions that benefit some children but harm others in the household. Thus, interventions designed to narrow socioeconomic disparities between families may inadvertently exacerbate inequalities within families.

Our findings also highlight the importance of future research assessing the importance of parental time compared to other inputs in the human capital production function. As mentioned earlier, we face a common limitation of RCTs in that we do not have full information on how households use their financial incentive payments. ${ }^{11}$ If households use their earnings on inputs that (directly or indirectly) benefit non-targeted siblings, knowing the marginal rate of technical substitution between these inputs and parental time in producing skills is of first-order importance. Prior research suggests that parental time ranks among the most important inputs for children at early ages, so we suspect that decreasing parental time but increasing access to other household resources will still negatively impact human capital formation in non-targeted siblings. Nevertheless, future work exploring the trade-off between parental time and other inputs at different ages would help us quantify the long-term impacts of intrahousehold time reallocation on skill formation.

\footnotetext{
${ }^{11}$ Some studies have addressed this challenge by collecting detailed expenditure data from households (see Macours, Schady, and Vakis 2012).
} 
Table 1: Summary Statistics

\begin{tabular}{|c|c|c|c|c|c|}
\hline VARIABLES & $\begin{array}{l}\text { Delayed } \\
\text { Payment }\end{array}$ & $\begin{array}{c}\text { Immediate } \\
\text { Payment }\end{array}$ & Difference & T-statistic & P-value \\
\hline & \multicolumn{5}{|c|}{ Panel A: Full sample of Parent Academy families } \\
\hline Target child is female & $\begin{array}{c}0.503 \\
(0.042)\end{array}$ & $\begin{array}{c}0.482 \\
(0.043)\end{array}$ & $\begin{array}{c}0.022 \\
(0.060)\end{array}$ & 0.363 & 0.719 \\
\hline Target child age & $\begin{array}{c}4.825 \\
(0.062)\end{array}$ & $\begin{array}{c}4.841 \\
(0.064)\end{array}$ & $\begin{array}{l}-0.016 \\
(0.089)\end{array}$ & -0.178 & 0.859 \\
\hline Black & $\begin{array}{c}0.421 \\
(0.041)\end{array}$ & $\begin{array}{c}0.423 \\
(0.042)\end{array}$ & $\begin{array}{l}-0.003 \\
(0.059)\end{array}$ & -0.045 & 0.964 \\
\hline Hispanic & $\begin{array}{c}0.455 \\
(0.041)\end{array}$ & $\begin{array}{c}0.445 \\
(0.043)\end{array}$ & $\begin{array}{c}0.010 \\
(0.059)\end{array}$ & 0.167 & 0.868 \\
\hline Target child has siblings & $\begin{array}{c}0.379 \\
(0.040)\end{array}$ & $\begin{array}{c}0.394 \\
(0.042)\end{array}$ & $\begin{array}{l}-0.015 \\
(0.058)\end{array}$ & -0.255 & 0.799 \\
\hline Mother's age & $\begin{array}{c}30.97 \\
(0.618)\end{array}$ & $\begin{array}{c}31.12 \\
(0.632)\end{array}$ & $\begin{array}{l}-0.153 \\
(0.886)\end{array}$ & -0.173 & 0.863 \\
\hline Baseline investment ${ }^{12}$ & $\begin{array}{c}2.517 \\
(0.235)\end{array}$ & $\begin{array}{c}2.250 \\
(0.223)\end{array}$ & $\begin{array}{c}0.267 \\
(0.326)\end{array}$ & 0.820 & 0.414 \\
\hline $\begin{array}{l}\text { Baseline cognitive score } \\
\text { (standardized) }\end{array}$ & $\begin{array}{c}0.001 \\
(0.095)\end{array}$ & $\begin{array}{l}-0.044 \\
(0.082)\end{array}$ & $\begin{array}{c}0.045 \\
(0.125)\end{array}$ & 0.358 & 0.721 \\
\hline $\begin{array}{l}\text { Baseline non-cognitive score } \\
\text { (standardized) }\end{array}$ & $\begin{array}{l}-0.035 \\
(0.100)\end{array}$ & $\begin{array}{c}0.096 \\
(0.085)\end{array}$ & $\begin{array}{l}-0.131 \\
(0.131)\end{array}$ & -1.003 & 0.317 \\
\hline \multirow[t]{2}{*}{ Observations } & 145 & 137 & 282 & 282 & 282 \\
\hline & \multicolumn{5}{|c|}{ Panel B: Families with at least one non-targeted sibling } \\
\hline Target child is female & $\begin{array}{c}0.382 \\
(0.066)\end{array}$ & $\begin{array}{c}0.481 \\
(0.069)\end{array}$ & $\begin{array}{l}-0.100 \\
(0.095)\end{array}$ & -1.046 & 0.298 \\
\hline Target child age & $\begin{array}{c}4.734 \\
(0.100)\end{array}$ & $\begin{array}{c}4.783 \\
(0.093)\end{array}$ & $\begin{array}{l}-0.049 \\
(0.137)\end{array}$ & -0.360 & 0.719 \\
\hline Black & $\begin{array}{c}0.400 \\
(0.067)\end{array}$ & $\begin{array}{c}0.333 \\
(0.065)\end{array}$ & $\begin{array}{c}0.067 \\
(0.093)\end{array}$ & 0.717 & 0.475 \\
\hline Hispanic & $\begin{array}{c}0.473 \\
(0.068)\end{array}$ & $\begin{array}{c}0.537 \\
(0.068)\end{array}$ & $\begin{array}{l}-0.064 \\
(0.096)\end{array}$ & -0.667 & 0.506 \\
\hline Sibling age $\mathrm{e}^{13}$ & $\begin{array}{c}6.890 \\
(0.574)\end{array}$ & $\begin{array}{c}7.737 \\
(0.516)\end{array}$ & $\begin{array}{c}-0.847 \\
(0.773)\end{array}$ & -1.095 & 0.276 \\
\hline Mother's age & $\begin{array}{c}31.83 \\
(0.926)\end{array}$ & $\begin{array}{c}32.27 \\
(0.818)\end{array}$ & $\begin{array}{l}-0.436 \\
(1.231)\end{array}$ & -0.354 & 0.724 \\
\hline Baseline investment & $\begin{array}{c}2.357 \\
(0.322)\end{array}$ & $\begin{array}{c}2.167 \\
(0.333)\end{array}$ & $\begin{array}{c}0.190 \\
(0.465)\end{array}$ & 0.410 & 0.684 \\
\hline Baseline cognitive score & $\begin{array}{c}0.165 \\
(0.144)\end{array}$ & $\begin{array}{l}-0.131 \\
(0.116)\end{array}$ & $\begin{array}{c}0.296 \\
(0.184)\end{array}$ & 1.607 & 0.111 \\
\hline Baseline non-cognitive score & $\begin{array}{c}0.113 \\
(0.137)\end{array}$ & $\begin{array}{c}0.260 \\
(0.133)\end{array}$ & $\begin{array}{l}-0.146 \\
(0.191)\end{array}$ & -0.768 & 0.444 \\
\hline Observations & 63 & 61 & 124 & 124 & 124 \\
\hline
\end{tabular}

Notes: All variables are used as controls in the regression analysis. Standard errors are in parentheses. Sibling age data were collected from the sibling survey, which was administered after the intervention began. All other data were collected prior to each family's participation in the program.

${ }^{12} 0$ corresponds to no hours on an average weekday, 1 corresponds to less than 1 hour, 2 corresponds to $1-2$ hours, 3 corresponds to 2-3 hours, 5 corresponds to 3-5 hours, and 6 corresponds to more than 5 hours.

${ }^{13}$ Average age of siblings if CHECC child has siblings 
Table 2: Effect of Immediate vs. Delayed Condition on Parent Academy Outcomes

\begin{tabular}{|c|c|c|c|}
\hline & $(1)$ & $(2)$ & (3) \\
\hline \multicolumn{4}{|c|}{ Panel A: Number of Classes Attended } \\
\hline Effect of Immediate vs. & 0.086 & 0.080 & 0.0263 \\
\hline Delayed Condition & $(0.065)$ & $(0.067)$ & $(0.067)$ \\
\hline Mean & 12.83 & 12.83 & 12.83 \\
\hline
\end{tabular}

Panel B: Homework GPA

$\begin{array}{lccc}\text { Effect of Immediate vs. } & 0.403 * * & 0.385^{* *} & 0.300^{* *} \\ \text { Delayed Condition } & (0.166) & (0.168) & (0.149) \\ \text { Mean } & 2.134 & 2.134 & 2.134 \\ & (0.0790) & (0.0790) & (0.0790)\end{array}$

Panel C: Total Earnings from Evaluations

$\begin{array}{lccc}\text { Effect of Immediate vs. } & 172.2^{* *} & 159.0^{* *} & 126.8^{* *} \\ \text { Delayed Condition } & (68.34) & (68.56) & (59.68) \\ \text { Mean } & 947.8 & 947.8 & 947.8 \\ & (33.39) & (33.39) & (33.39)\end{array}$

Panel D: Total Earnings from Assessments

$\begin{array}{lccc}\text { Effect of Immediate vs. } & 93.05^{* *} & 90.37 * & 68.96^{*} \\ \text { Delayed Condition } & (45.84) & (46.41) & (38.47) \\ \text { Mean } & 547.7 & 547.7 & 547.7 \\ & (21.58) & (21.58) & (21.58)\end{array}$

\begin{tabular}{lccc}
\hline Observations & 326 & 326 & 326 \\
Demographic controls & & YES & YES \\
Additional Controls & & & YES \\
\hline \hline
\end{tabular}

Note: Effect of immediate compared to delayed payment. Panel A reports negative binomial regression results where outcome is the number of classes attended. Panel B reports OLS results on homework GPA. Panel C reports OLS results on evaluation earnings, which depend on absolute evaluation score. Panel D reports OLS results on assessment earnings, which depend on improvements in assessment score. All regressions control for school year and total years in CHECC. Demographic controls: target child's gender, age, race, and baseline parental investment. Additional controls: average sibling age, mother's age, target child's baseline cognitive score, and target child's baseline noncognitive score. Standard errors clustered at family level in parentheses. $* * * \mathrm{p}<0.01, * * \mathrm{p}<0.05, * \mathrm{p}<0.1$ 


\section{Figure 1: Ordered Probit Estimates of Experimental Condition on Investment}

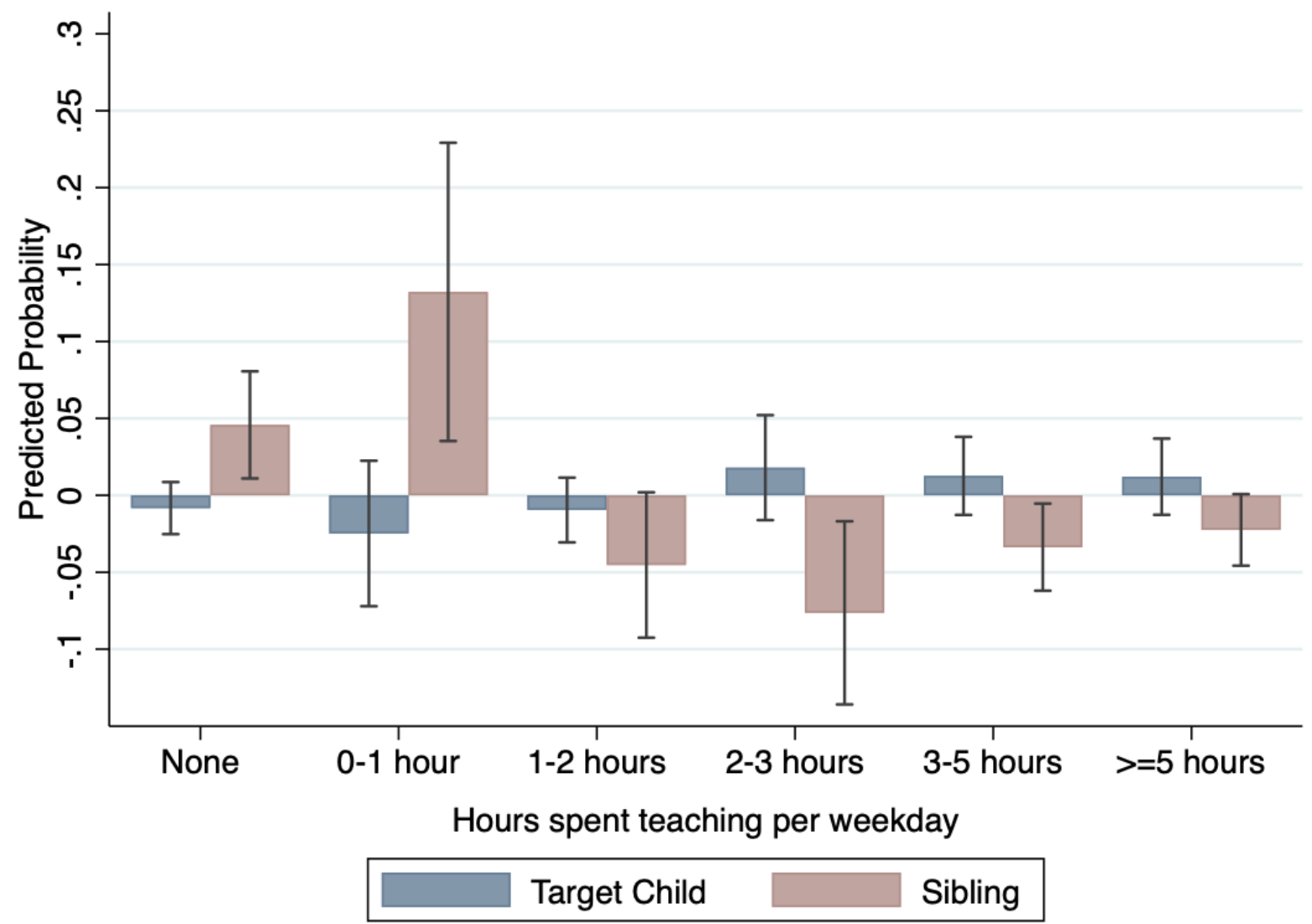

Note: Predicted treatment effect on time spent teaching target children and non-targeted siblings. Probabilities estimated from ordered probit regressions controlling for school year, total years in CHECC, target child's age, target child's gender, race, and baseline parental investment. 90\% confidence intervals. Appendix Tables A2-A3 provide regression coefficients across multiple alternative specifications. 


\section{Figure 2: Parental investment in target child versus sibling}

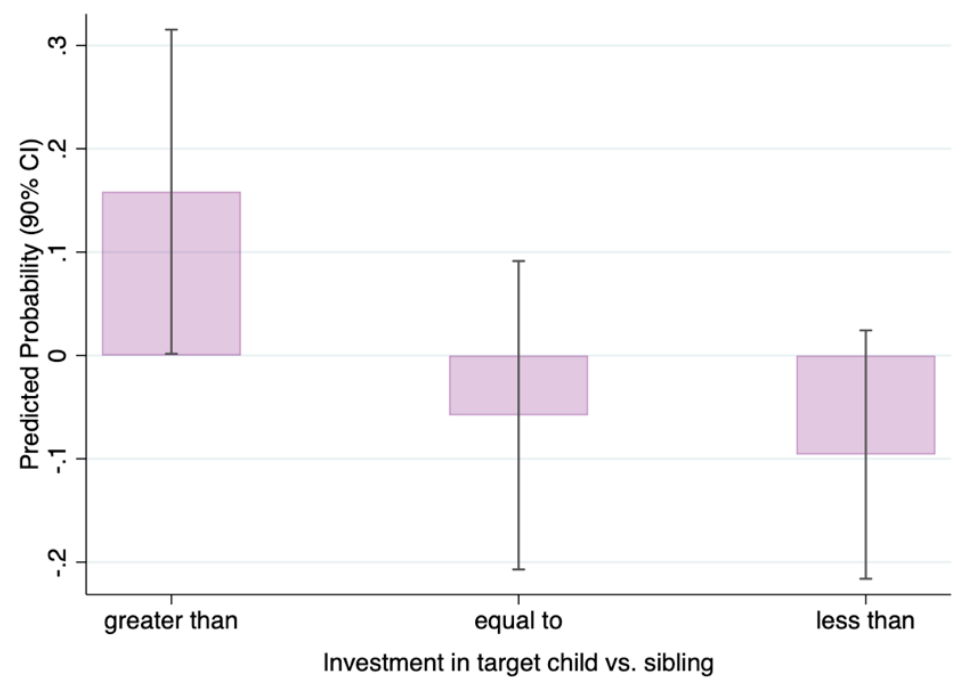

Notes: Predicted treatment effect on whether parents invested more time, equal time, or less time in target children than in non-targeted siblings. Probabilities estimated from probit regressions controlling for school year, total years in CHECC, target child's age, target child's gender, race, and baseline parental investment. $90 \%$ confidence intervals. 


\section{Figure 3: Additional treatment effect of having no sibling close to target child age}
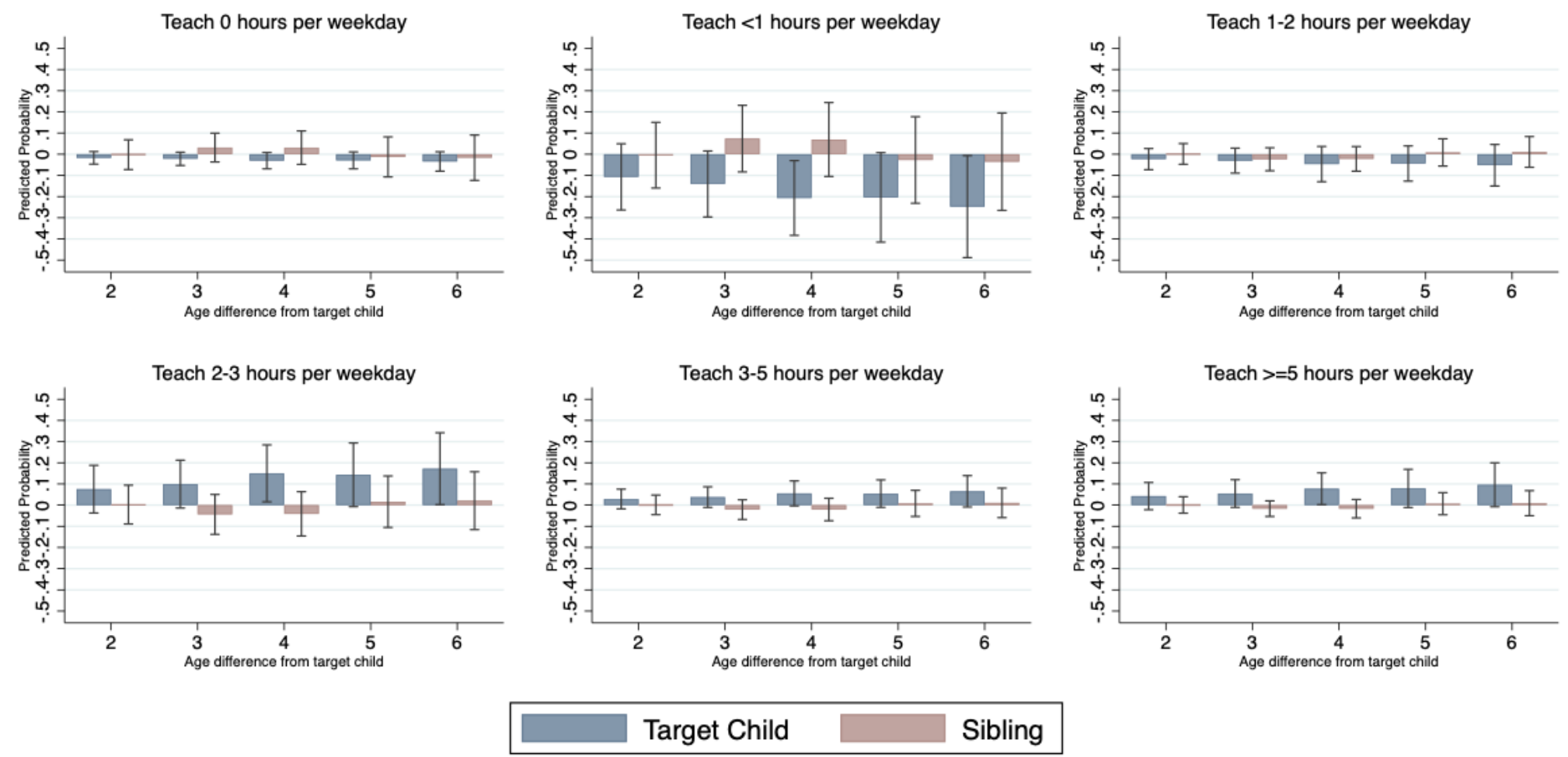

Notes: Estimated difference in treatment effect among families with no siblings close to the target child's age compared to families with siblings close to target child's age. The difference in treatment effect, expressed in terms of the difference in predicted probabilities, is calculated from the coefficient $\beta_{3}$ in equation (2). Regressions control for school year and total years in CHECC. 90\% confidence intervals. 


\section{References}

Baird, S., McIntosh, C., Ozler, B., 2011. Cash or condition? Evidence from a cash transfer experiment. Quarterly Journal of Economics 126, 1709-1753.

Barrera-Osorio, F., Bertrand, M., Linden, L.L., Perez-Calle, F., 2011. Improving the design of conditional transfer programs: evidence from a randomized education experiment in Colombia. American Economic Journal: Applied Economics 3, 167-195.

Bustelo, M., 2011. Three essays on investments in children's human capital (doctoral dissertation). University of Illinois at Urbana-Champaign, Urbana-Champaign, IL.

Cohen, J., Cohen, P., 1975. Applied Multiple Regression/Correlation Analysis for the Behavioral Sciences, second ed. Lawrence Erlbaum Associates Inc., New Jersey.

Cotton, Christopher S. and Brent R. Hickman and John A. List and Joseph Price and Sutanuka Roy, 2020. Productivity Versus Motivation in Adolescent Human Capital Production: Evidence from a Structurally-Motivated Field Experiment, Field Experiments Website working paper.

Del Boca, D., Flinn, C., Wiswall, M., 2014. Household Choices and Child Development. The Review of Economic Studies 81, 137-185.

Del Boca, D., Flinn, C., Wiswall, M., 2016. Transfers to Households with Children and Child Development. The Economic Journal 126, F136-F183.

Dunn, L.M., Dunn, D.M., Bulheller, S., Hacker, H., 1965. Peabody Picture Vocabulary Test. American Guidance Service, Minnesota.

Ferreira, F.H.G., Filmer, D., Schady, N., 2009. Own and sibling effects of conditional cash transfer programs: theory and evidence from Cambodia. Research on Economic Inequality 25, 259-298.

Fontenot, K., Semega, J., Kollar, M., 2018. Current population reports, P60-263, income and poverty in the United States: 2017. U.S. Census Bureau.

Fryer, R., Levitt, S., List, J., 2015. Parental incentives and early childhood achievement: A field experiment in Chicago Heights. NBER Working Paper 21477.

Harrison, Glenn W. and John A. List, 2004. Field Experiments, Journal of Economic Literature, 42(4), pp. 1009-1055.

Heckman, J.J., 2006. Skill formation and the economics of investing in disadvantaged children. Science 312, 1900-1902.

Heckman, J.J., 2008. Schools, skills, and synapses. Economic Inquiry 46, 289-324. 
Heckman, J.J., Karakapula, G., 2019. Intergenerational and intragenerational externalities of the Perry Preschool Project. Human Capital and Economic Opportunity Global Working Group Working Paper 2019-033.

Hill, C.R., Stafford, F.P., 1974. Allocation of Time to Preschool Children and Educational Opportunity. The Journal of Human Resources 9: 323-341.

J-PAL, 2013. J-PAL Youth Initiative Review Paper. Abdul Latif Jameel Poverty Action Lab, Massachusetts.

Juhn, C., Rubinstein, Y., Zuppann, C., 2015. The quantity-quality trade-off and the formation of cognitive and non-cognitive skills. NBER Working Paper 21824.

Leibowitz, A., 1974. Home Investments in Children. The Journal of Political Economy 82, S111S131.

Leibowitz, A., 1977. Parental Inputs and Children's Achievement. The Journal of Human Resources 12, 242-251.

List, John A. 2011. The Market for Charitable Giving, Journal of Economic Perspectives, 25(2): 157-180.

List, John A. 2020. Non Est Disputandum De Generalizability? A Glimpse into the External Validity Trial, NBER Working Paper No. w27535.

Macours, K., Schady, N., Vakis, R., 2012. Cash Transfers, Behavioral Changes, and Cognitive Development in Early Childhood: Evidence from a Randomized Experiment. American Economic Journal: Applied Economics 4, 247-73.

Millan, T.M., Barham, T., Macours, K., Maluccio, J.A., Stampini, M., 2019. Long-term impacts of conditional cash transfers: review of the evidence. The World Bank Research Observer 34, 119-159.

Shrestha, S.A., Palaniswamy, N., 2017. Sibling rivalry and gender gap: intrahousehold substitution of male and female educational investments from male migration prospects. Journal of Population Economics 30, 1355-1380.

Smith-Donald, R., Raver, C.C., Hayes, T., Richardson, B., 2007. Preliminary construct and concurrent validity of the Preschool Self-Regulation Assessment (PSRA) for field-based research. Early Childhood Research Quarterly 22, 173-187.

Takamatsu, S., 2011. Conditional cash transfer programs and spillover effects within households in Nicaragua. Unpublished manuscript. 
Willoughby, M.T., Wirth, R.J., Blair, C.B., 2012. Executive function in early childhood: Longitudinal measurement invariance and developmental change. Psychological Assessment 24, 418-431.

Woodcock, R.W., McGrew, K.S., Mather, N., 2001. Woodcock Johnson Tests of Achievement. Riverside Publishing, Illinois. 